\title{
Perception of Preceptor and Student Nurse Partnership on Clinical Teaching and Learning
}

\author{
David Kaniaru ${ }^{1}$, , Elijah Nyagena ${ }^{2}$, Nebart Kathuri ${ }^{3}$, Alex Chebor ${ }^{1}$ \\ ${ }^{1}$ School of Nursing, Midwifery and Paramedical Sciences, Masinde Muliro University of Science \& Technology (MMUST), Kakamega, \\ Kenya \\ ${ }^{2}$ Department of Nursing, University of Kabianga (UoK), Kapkatet, Kenya \\ ${ }^{3}$ Department of Nursing Sciences, Kenya Methodist University (KeMU), Meru, Kenya
}

Email address:

kaniaga@gmail.com (D. Kaniaru), alexchebor@gmail.com (A. Chebor)

${ }^{*}$ Corresponding author

\section{To cite this article:}

David Kaniaru, Elijah Nyagena, Nebart Kathuri, Alex Chebor. Perception of Preceptor and Student Nurse Partnership on Clinical Teaching and Learning. American Journal of Nursing Science. Vol. 5, No. 4, 2016, pp. 141-145. doi: 10.11648/j.ajns.20160504.13

Received: June 13, 2016; Accepted: June 27, 2016; Published: July 13, 2016

\begin{abstract}
Preceptorship is a model of clinical training in which a qualified nurse, referred to as a preceptor, is assigned to one or a group of nursing students, for the purpose of facilitating learning in the clinical setting. This study was done in Maua Methodist \{M. M. H (Meru County, Kenya)\} and Preyspeterian Churches East Africa (P. C. E. A) Chogoria (Tharaka-Nthi County, Kenya) hospitals in Meru, Kenya and its main objective was to determine the perceived need for preceptor-student nurse partnership in nursing training institution. A sample size of one hundred (100) respondents was randomly selected from a target population of one hundred and eighty (180) preceptees, by use of convenient sampling method. Ten (10) preceptors were also selected conveniently to participate in the study. One hundred and ten (110) questionnaires were distributed out of which ninety nine (99) were received back \{(ninety-one -91) from preceptees and eight (8) from preceptors) $\}$. Both, qualitative and quantitative descriptive survey designs was utilized. Descriptive statistics were used to analyse the resultant data. Regarding to the importance of having preceptors, results showed that eighty five out of ninety $\{85 / 90(94.44 \%)\}$ of the student nurses agreed that they are important while three (33.33\%) disagreed. Eight out of nine $\{8 / 9(88.88 \%)\}$ of the preceptors agreed on the importance of preceptorship while one $\{1 / 9(11.11 \%)\}$ was not sure. The reasons according to students why they need these preceptors included; provision of directions and guidelines (90\%), supervision (79\%), resolve clinical conflicts between them and staff nurses $(76 \%)$ and to have a role model to emulate $(83 \%)$. For the preceptors - to have a good working environment (78\%) and to act as role model (56\%). Hence the need for the student- preceptor partnership during students nurses training period.
\end{abstract}

Keywords: Partnership, Perception, Preceptor, Student Nurse

\section{Introduction}

The term preceptor was first used in the $15^{\text {th }}$ century, meaning a tutor or instructor in nursing [1]. Preceptorship emerged then as the "reality shock" that students were experiencing at the transition phase from theory to practice and from a student life to a professional nurse. It then became the focus of concern in the nursing profession [2] hence, was adopted as a way for preparing clinically competent graduate nurses who would be able to assume full patient care as soon as they are employed [3].
Preceptorship facilitates the development of the knowledge, clinical skills and professional attitude through guidance, supervision, role modelling, and personal development. Preceptorship study conducted in the Intensive Care Units in United Kingdom, revealed that new staff and students need to be oriented immediately when they are deployed to any unit as this saved a lot of time wasted due to disorientation [1] [19].

\subsection{Purpose of Study}

This study sort to explore the perception of preceptor and 
student nurses partnership during training period. This was because of the evaluation of the feedback given by students pursuing their second and third year nursing courses, in Maua Methodist and Chogoria P. C. E. A hospital nursing schools in Meru Kenya, on the issues of preceptorship.

\subsection{Contribution of This Paper}

Study findings will benefit preceptors, student nurses, and training institutions administrators towards decision making based on evidence, with an aim of improving the quality of clinical education as well as the care of patients.

\section{Materials and Methods}

Descriptive survey design was used in this study. This study was conducted at Maua Methodist (Meru County, Kenya) and P. C. E. A Chogoria (Tharaka-Nthi County, Kenya) hospitals. This two, institutions have been approved as nursing training schools by Nursing Council of Kenya (NCK). The target population comprised of second and third year nursing students who were at the time of study registered at Maua Methodist and P. C. E. A Chogoria Medical Training colleges. Maua M. T. C had sixty (60) and Chogoria had one hundred and twenty (120) eligible students. All the ten (10) selected preceptors were eligible. Four (4) preceptors came from Maua M. T. C and six (6) came from Chogoria M. T. C. The total population of preceptors and preceptees were one hundred and ninety (190). First year students were excluded since they had not had sufficient clinical experience nor had sat for any clinical examination.

\subsection{Sampling Procedure and Sample Size}

In a survey research design of study, a minimum sample size of one hundred (100) subjects are adequate as long as none of the subgroups is less than 20 respondents [4]. This was adopted, though not for the cases of preceptors. A ratio method was used to get a proportional sample size of preceptees in each institution, that is 60: 120 (1: 2) which translated to $\{1 / 3 * 100+2 / 3 * 100\}$. The resultant sample size was 100 for preceptees and 10 for preceptors. Simple random sampling method was used to pick the preceptees while, convenient sampling method was used to pick the preceptors. Informed consent was sought from the participants and the two institutions.

\subsection{Research Instruments}

Data was collected using both open and closed ended questionnaires which had a Likert like scale of 0-3 answers. This was applied to both the preceptors and the preceptees. Face and content validity was done by the subject expect. Pre-testing was done in Nkubu M. T. C, Meru Kenya. The reliability co-efficient of the student nurses was 0.66 while that of the preceptors was 0.77 . The pilot test results necessitated revision of the preceptees instrument in order to raise the reliability coefficient to at least 0.7 [5] [6], which was later done (reliability coefficient achieved at-0.71) and used to collect the data.

\subsection{Statistical Analysis}

We carefully checked the data so as to identify any ambiguous, contradicting responses as well as incomplete questionnaires. For qualitative data, we categorized according to their themes and analysis done and for quantitative data, descriptive statistics were used. These included measures of central tendency such as mean, mode and median. The results were presented using frequency tables, ratios and percentages.

\section{Results}

\subsection{Response Rate}

Study response rate showed that all participants received questionnaires and only ninety nine (99) questionnaires were received back. Preceptors had nine (9) out of ten $\{9 / 10$ $(90 \%)\}$ return rate and for preceptees -from Maua Methodist Hospital had thirty two out of thirty three $\{32 / 33(97 \%)\}$ return rate, while those from P. C. E. A Chogoria hospital had $86.56 \%$ return rate. The overall response rate was $90 \%$, which we found acceptable for analysis.

\subsection{Preceptor's Availability}

Table 1. Preceptors Availability in M. M. H and P. C. E. A Chogoria Hospitals.

\begin{tabular}{lll}
\hline Responses & Preceptors \% & Student nurses \% \\
\hline Yes (available) & $(5 / 9) 55.56 \%$ & $(44 / 79) 68.4 \%$ \\
No (not available) & $(3 / 9) 33.33 \%$ & $(16 / 79) 20.3 \%$ \\
Not sure & $(1 / 9) 11.11 \%$ & $(3 / 79) 3.8 \%$ \\
Not applicable & 0 & $(6 / 79) 7.6 \%$ \\
Total & 100 & 100 \\
\hline
\end{tabular}

Results in table 1 above, show that five (5) out of nine $\{5 / 9(55.6 \%)\}$ of the preceptors indicated "yes", to preceptorship availability at their training hospitals, three (3) out of nine $\{3 / 9(33.33 \%)\}$ indicated "no", and one (1) out of nine $\{1 / 9(11.11 \%)\}$ indicated "not sure" respectively.

Similarly, fifty four (54) out of seventy nine $\{54 / 79$ $(68.4 \%)\}$ of the students indicated "yes", sixteen (16) out of seventy nine $\{16 / 79(20.3 \%\}$ indicated "no". While, three (3) out of seventy nine $\{3 / 79(3.8 \%)\}$ indicated "not sure". Six (6) out of seventy nine $\{6 / 79(7.6 \%)\}$ did not respond.

\subsection{Preceptors Population Size at Any Given Time in the Hospital Training Institution}

Table 2. The number of preceptors as per nursing training institutions at any given time.

\begin{tabular}{lll}
\hline Institution & $\begin{array}{l}\text { Mean No. of Preceptors } \\
\text { at a site at any given time }\end{array}$ & $\begin{array}{l}\text { Response } \\
\text { rate } \%\end{array}$ \\
\hline Chogoria P. C. E. A Hospital & & \\
\hline $\begin{array}{l}\text { Student nurses } \\
\text { Preceptors }\end{array}$ & 6 & $(25 / 33) 76 \%$ \\
$\begin{array}{l}\text { M. M. H } \\
\text { Student nurses }\end{array}$ & 3 & $(2 / 3) 67 \%$ \\
\hline
\end{tabular}




\begin{tabular}{lll}
\hline Institution & $\begin{array}{l}\text { Mean No. of Preceptors } \\
\text { at a site at any given time }\end{array}$ & $\begin{array}{l}\text { Response } \\
\text { rate } \%\end{array}$ \\
\hline Chogoria P. C. E. A Hospital & & \\
\hline Preceptors & 0 & 0 \\
Total & 10 & \\
\hline
\end{tabular}

Results in table 2 above shows that at Chogoria P. C. E. A hospital, twenty five out of thirty three student nurses $\{25 / 33$ $(76 \%)\}$ reported an average of six (6) preceptors at their station at any given time, though two out of three $\{2 / 3$ $(67 \%)\}$ preceptors interviewed, had a different response, they stated that they are only three (3) at any given time at their site. Similar report was also found in M. M. H, as shown in table 2 above. Because of these different responses (from student nurses and preceptors), we went further to find out why; and the answer was that most of the students seem not to understand the difference between preceptor and a bedside nurse roles.

\subsection{The Ratio of Preceptors to Student Nurses}

With regards to preceptors to students nurse ratios, results indicated that eighty six (86) out of ninety nine $\{86 / 99$ $(86 \%)\}$ of the student nurses stated a ratio ranging from 1: 13 and 1: 32. While, eight (8) out of nine $\{8 / 9(89 \%)\}$ of the preceptors stated a ratio between 1: 14 and 1: 20. A variation higher than that in the literature. The preceptorship model that originated from Florence Nightingale recommends that, one student nurse be precepted by a single nurse or one nurse is to work with a small group of student nurses [7]. It is also recommended that a faculty member be responsible for supervising the practical experiences of the student nurses. Evaluation results of this model showed positive outcomes on the part of preceptors, students and faculty members. Students gained more confidence in undertaking nursing procedures. At the same time, faculty members spared some of their time to address other learning issues. The beginning and advanced student nurses be taught in small groups by one preceptor as this would enhance clinical teaching and learning [8].

\subsection{Importance of Preceptors in a Training Nursing Institution}

Regarding to the importance of having preceptors, results show that eighty five out of ninety $\{85 / 90(94.44 \%)\}$ of the student nurses agreed that they are important, and three out of ninety $(33.33 \%)$ disagreed, while, eight out of nine $\{8 / 9$ $(88.88 \%)\}$ of the preceptors agreed and one out of nine $\{1 / 9$ $(11.11 \%)\}$ was not sure. In this case, significant proportion of both preceptors and students believed that preceptors were of great importance towards promoting clinical learning experience as stated in the literature [9].

\subsection{Other Perceived Reasons by Student Nurses on the Need for Them to Partner with Preceptors}

(1) To be provided with clinical directions and guidelines.

Results show that eighty one out of ninety $\{81 / 90(90 \%)\}$ of the student nurses felt that, they needed the company of a qualified nurse to guide them on the day to day clinical teaching and learning activities since they lacked confidence in performing nursing procedures as evidenced by the following statements;

"Preceptors help in directing student nurses in nursing process." "They help and guide student nurses on solving problems that they experience during clinical placement."

Student nurses and new nurses usually experience some stress during their first clinical placement or year of practice respectively; due to lack of confidence, concerns about relationship with peers and preceptors, losing sight of the big picture, time constrains, fear of causing patients harm and, feeling incompetent that is; lack of critical thinking and clinical knowledge [10].

(2) To be supervised.

According to the study results, seventy eight out of ninety nine $\{78 / 99(78.79 \%)\}$ of student nurses mentioned the phrase "student supervision".

"Preceptors oversee student nurses in the clinical area".

"They check out how students behave or conduct themselves while in the wards", and finally "we students like being supervised."

An indication that majority of the students felt inadequate without supervision. They placed the entire trust on the Integrated Clinical Preceptor Model [11]. The preceptor acts as the clinical teacher or role model to his students and others.

(3) To improve students clinical confidence level.

Sixty three out of ninety nine $\{63 / 99(64 \%)\}$, student nurses acknowledged that; their clinical experience had remarkably improved due to the inputs made by their preceptors during the period of interaction as implied by the statement.

"I am now able to perform nursing procedures well because primary (bed side) nurses were there for me when I needed them most."

The above felt need was supported by Maslow hierarchy of needs who stated that:

"people are motivated by needs that remain unsatisfied, and that certain lower factors have to be satisfied in order for higher needs to be recognized as unfulfilled, for example, general survival, physiological, love, safety, and self-esteem "[12].

(4) To solve clinical conflicts among students and others

Seventy five out of ninety nine $\{75 / 99(76 \%)\}$ student nurses reported that, they had experienced conflicts with other clinical staff as well as among themselves. Preceptors intervened and resolved the conflict on time, hence promoting a healthy working relationship.

(5) To teach student nurses.

Ninety one of ninety nine $\{91 / 99(92 \%)\}$ student nurses stated that, they were able to translate theory knowledge that had been taught in class into a real life situation during clinical placement. This was aided by the availability of both preceptors and the primary nurses as indicated by the following statement.

"We need preceptors in order to promote better 
understanding of what we learn in class while in clinical placement."

(6) To act as a clinical role model.

Eighty two out of ninety nine $\{82 / 99(83 \%)\}$ of student nurses stated that they had emulated majority of their preceptors in their daily learning in clinical placements since majority of their preceptors presented themselves well.

(7) To promote reflective thinking, growth and development.

Ninety out of ninety nine $\{90 / 99(91 \%)\}$ student nurses stated that they needed somebody to stimulate their thinking, based on the challenges of the day to day, of nursing care.

College learners pass through three stages of intellectual development before becoming good critical thinkers in their field of practice [13]. These stages include; Dualism, Relativism and Reflectivism.

In the dualism phase, young or unsophisticated thinkers tend to see the world in bipolar terms: e.g. black and white, good and bad, e.tc, in this case there were some student nurses who saw the black and white world during their first clinical placement. Clinical environment was totally new; tasks allocated did not make any meaningful sense to them, until later stages of their training, especially during third and fourth years. They also had a "Cognitive egocentrism" that is, they found it difficult to entertain others points of view including their colleagues and those of none nursing staff [1].

Twenty four out of ninety nine $\{24 / 99(24 \%)\}$ student nurses reported that they had difficulty in learning new skills, at the beginning of training since it had not been taught in classroom- preceptors come in handy to help them, as illustrated in the statement below;

"Preceptor helped me to see things differently especially when I was a junior student nurse since I disliked learning what we had not been taught in class, actually I thought it was wrong."

In the relativism phase- as student nurses progress well with their careers, they come to understand that there was no often a single rightful prescribed answer to most of the problems that they had experienced earlier, and that some questions had no immediate answers but were demanding an individualized applications of his/her previous successive occurred experience outcomes towards handling issues at hand as evidenced by the quote below.

"My clinical instructor has always been using the Nursing Care Plan (NCP) evaluation outcomes on given patients to apply in similar cases that I was being faced with. This helped me to crack my thinking deeper, so I need more of them so that they can keep me on my toes on daily basis."

\subsection{Other Perceived Reasons by Preceptors on the Need for Them to Partner with Student Nurses}

(1) To promote good learning environment.

Seven out of nine $\{7 / 9(78 \%)\}$ preceptors agreed that, in order for clinical teaching and learning to be effective, preceptors and student nurses had to work together harmoniously. Major role for preceptor is to support students to conceptualize theory and translate it into real nursing practice. This view was supported by some preceptors statements like;

"A preceptor works closely with student nurses to identify their level of knowledge, skills gap and attitude on nursing and assist them where necessary." "I like working with student nurses who are eager to learn since I would create an impact on their lives, in fact they are our tomorrow's nurses."

(2) To act as clinical role model.

Five out of nine $\{5 / 9 \quad(56 \%)\}$ of the preceptors acknowledged that, their behaviour when working with student nurses had a direct impact on the student's behaviour, either positively or negatively. Positively, student nurses had learned more about professionalism and negatively the learned shortcut method of performing nursing procedure which endangers patients and clients health care.

(3) To promote coping and relating mechanism.

Three out of nine $\{3 / 9(33 \%)\}$ of preceptors felt that, it was their role to help student nurses to adjust to their new roles in clinical placements. This made the work of primary nurse easier;

"They relieve the primary nurse the heavy duty of counselling students who have issues with the new tasks that are assigned to them."

\section{Discussion}

In general, this study showed a strong positive acceptance by the preceptors and student nurses on the need for them to work together in clinical teaching and learning. Both preceptors and students felt that they benefitted from that relationship.

A Preceptor, in nursing education, is a key person and the appropriate qualities and characteristics they possess are very critical in ensuring a successful orientation process offered to student nurses on their clinical teaching and learning [14] [19]. Data on preceptor availability showed that both training institutions had below minimum preceptors' population as compared to similar studies conducted in Northern America which showed that one nurse and preceptor is responsible for the clinical teaching of a single student [15] \& [18].

Despite the fact that they were few, preceptors nevertheless contributed significantly towards clinical teaching and learning process for their student nurses. There was some collaboration among these two parties which worked well to meet teaching and learning objectives of the student nurses, which is supported by the 'collaborative perceptive type of model' [16].

Beginner and advanced student nurses were mixed together in all clinical rotation in order to share their learned experience together. During clinical placement faculty member offered teaching support to the preceptors in tandem with the leaners needs [7] [18]. Faculty members must always be present in the clinical area during students' clinical experience in order to assist the preceptor in planning students' learning experiences among other needs.

Students identified the following as major reasons why 
they needed preceptors; to provide them with directions and guidelines, supervision, aid at increasing their confidence, resolve clinical conflicts between them and staff nurses, to have a role model to emulate and finally to cope and adjust with the dynamics of teaching and learning processes [17].

\section{Conclusion}

Generally, the perception on preceptor and nursing student partnership in clinical teaching and learning during practice placements was positive, since majority of the preceptors and student nurses benefited by working together. Students gained more confidence in undertaking perceived threatened tasks when left alone after the partnership. They positively took their preceptors as a surrogate professional guide though not all preceptors were able to meet their needs due to either personality indifference, lack of sufficient experience and preceptors' insufficiency. It also indicated how successful partnership would be developed and sustained among preceptors and student nurses if preceptorship is embraced to the fullest. However, though the study was focused on nursing education, the findings may apply to other health science disciplines, including medicine and physiotherapists.

\section{References}

[1] Peirce, A., (2002). Preceptorial Students View of their Clinical Experience. Journal of Nursing Education, 30, 6, 244-250.

[2] Kramer M., (1999). Reality Shock: Why Nurses Leave Nursing. USA: St. Louis. The C. V Mosby Company.

[3] Mytric, F., \& Yonge, O., (2002). Enhancing Critical Thinking in The Preceptorship Experience in Nursing Education. Journal of Advance Nursing, 45 (4), 371-380.

[4] Kathuri N. J., Pals, D. (1993). Introduction to Educational and Educational Research. Njoro Ergaton: University Educational Media Centre. Kenya.

[5] Cronbach L. J., (1951). Coefficient Alpha and the Internal Structure of Tests. Journal of Extension Psychometrika. 16, 297-334.

[6] Rose Marie Neiswiadomy., (2004). Foundation of Nursing Research. New Jersey: Prentice Hall.
[7] Philips S. J., and S. H. Kaempfer., (2004). "Clinical Teaching Associate Model. Implemenation In A Community Hospital Setting". Journal of Professional Nursing, vol. 3, no. 3, pp. 165-175.

[8] Baxter P., (2007). Model of Cinical Supervision: Bridging the Theory-Practise Gap. Nursing Education in Practice, 7 (2), 103-111.

[9] Fulton J., Bohler A Hansen G. S Kauffeldt A., and DeWitt, A., (2007). Creating a Collaborative Partnership between Academia and Service. The Journal of Nursing Education, 41 (12), 518-523.

[10] Spears M. W., (1998). The Benefits of Preceptorships. Britain: The Bath press.

[11] Alynn P., Barbara, Mary F., (1996). Nursing Models for Practice. Landon: Educational and Professional Press.

[12] Anderson P., Floyd J., (2004). How Nurse Preceptor Influence New Graduates. Critical Care Nurse-Supplement. 4. 129-130.

[13] Stone C. L., \& Rowels., (2002). What Reward do Clinial Preceptor in Nursing Think Are Important? Journal for Nursing, 18 (3), 162-166.

[14] Landmark B. T., Hansen G. S., Bjone I. \& Bohler A., (2003). Evaluation by Nurses and Students of A New Assessment From For Clinical Nursing Education. Journal of Caring Sciences, 12 (6), 834-841.

[15] Benner P., (1999). From Novice to Expert: Excellence and Power in Clinical Nursing Practice. Menlo Park, Califonia: Addison-Wesley Publishing Company.

[16] Usher K, N. C., (1999). An Exploration of the Preceptor Role, Preceptor's Perceptions, Benefit, Reward, Supports and Commitment to the Preceptor Role. Journal of Advanced Nursing, 29: 506-514.

[17] Stevenson M., Doorley. J., Moodenman G, \& BensonLandau., (1995). The Preceptor Experience: A qualitative Study of Preceptions of Purse Preceptors in Nursing think are Important? Journal of Nurses in Staff Developement, 18 (3), 162-166.

[18] Yonge O., \& Myrick F., (2004). Precepting an Unsafe Student: The Role of the Faculty. Nurse Education Today 28 (2), $227-$ 231.

[19] Mallete, S. Loury., M. K. Engelke, and A. Andrews. (2005). Nursing Educator. The Intergrative Clinical Preceptor Model: A New Method for Teaching Undergraduate Community Health Nursing,"Vol. 30, no. 1, pp. 21-26. 